\title{
Evaluating the quality of lymphadenectomy in lung cancer resections: a narrative review
}

\author{
Jahnavi Kakuturu, Ghulam Abbas, Alper Toker \\ Department of Cardiovascular and Thoracic Surgery, West Virginia University, Morgantown, WV, USA \\ Contributions: (I) Conception and design: J Kakuturu, A Toker; (II) Administrative support: G Abbas, A Toker; (III) Provision of study materials or \\ patients: J Kakuturu, A Toker; (IV) Collection and assembly of data: J Kakuturu, A Toker; (V) Data analysis and interpretation: J Kakuturu, G Abbas, \\ A Toker; (VI) Manuscript writing: All authors; (VII) Final approval of manuscript: All authors. \\ Correspondence to: Alper Toker, MD. Department of Cardiovascular and Thoracic Surgery, West Virginia University School of Medicine, 1 Medical \\ Center Drive, Box 8500, Morgantown, WV 26505, USA. Email: salpertoker@gmail.com.
}

Background and Objective: Assessment of hilar and mediastinal lymph nodes at the time of resection for lung cancer has been recognized as a key aspect of surgical treatment. Although the value of lymphadenectomy in lung cancer staging and treatment has been established, specific guidelines as to the number and location of lymph nodes considered to be adequate, vary among societies, institutions, and surgeons. Additionally, many lung resections fail to meet any of the proposed criteria for lymph node examination. The objective of this article was to review the current guidelines on intrathoracic lymph node assessment for lung cancer resections, examine current practice patterns, report survival differences with varying levels of lymph node dissection, and propose methods to improve quality of lymphadenectomy based on our experience.

Methods: To find relevant articles for the narrative review, the PubMed database was used to search for the following key terms and their combinations: "lymphadenectomy", "lymph node staging", "lung cancer", "NSCLC", "lung surgery", "lung resection”, "lobectomy”, "segmentectomy”, "wedge resection”, "quality”, and "extent". The search was limited to English-language publications. A total of 33 articles were examined and publication years ranged from 1951 to 2021.

Key Content and Findings: Intrathoracic lymph node staging includes assessment of intrapulmonary, hilar, and mediastinal lymph nodes. Recommended guidelines for adequate staging are outlined within the article. Findings suggest that many patients are subject to inadequate lymph node evaluation and that survival may be decreased in this population.

Conclusions: Systematic mediastinal lymph node dissection is recommended in all type of surgeries for lung cancer, whether robotic surgery, video-assisted thoracoscopic surgery (VATS), or an open thoracotomy. There should be no difference in each technique as to the number of stations and quantity of lymph nodes examined, in order for lung cancer resection to be considered complete.

Keywords: Lung cancer; lymphadenectomy; quality

Received: 17 August 2021; Accepted: 06 December 2021; Published: 30 March 2022.

doi: 10.21037/asj-21-80

View this article at: https://dx.doi.org/10.21037/asj-21-80

\section{Introduction}

Lung cancer is the second most commonly diagnosed cancer worldwide and the leading cause of cancer related mortality (1). Complete resection remains the mainstay of treatment for non-metastatic disease and is important for long term survival. Assessment of hilar and mediastinal lymph nodes at the time of surgical resection has been recognized as a key aspect since the 1950s (2). This practice serves to provides prognostic information and to clear disease harbored within the lymph nodes. Five-year survival decreases significantly 
Table 1 The search strategy summary

\begin{tabular}{ll}
\hline Items & Specification \\
\hline Date of Search & $07 / 06 / 2021$ \\
Databases and other sources searched & PubMed \\
Search terms used & "lymphadenectomy", "lymph node staging", "lung cancer", "NSCLC", "lung surgery", "lung \\
& resection", "lobectomy", "segmentectomy", "wedge resection", "quality", and "extent" \\
Timeframe & $1951-2021$ \\
Inclusion criteria & All study designs, English language only \\
Selection process & Article selected by first author and senior author \\
\hline
\end{tabular}

as pathologic lymph node $(\mathrm{pN})$ stage increases, from $75 \%$ in $\mathrm{pN} 0$, to $50 \%$ in $\mathrm{pN} 1,38 \%$ in $\mathrm{pN} 2$, and $32 \%$ in $\mathrm{pN} 3$ disease, for patients who have undergone complete resection (3). Clinical staging may underestimate $\mathrm{pN}$ status in over $30 \%$ of patients, resulting in inadequate adjuvant therapy and decreased survival $(4,5)$. Surgical assessment of intrathoracic lymph node status therefore becomes crucial.

Although the value of lymphadenectomy in lung cancer staging and treatment has been established, specific guidelines as to the number and location of lymph nodes considered to be adequate, vary among societies, institutions, and surgeons. Prior studies have reported wide variability in the number of lymph nodes resected with lung cancer specimen, ranging from 0 to greater than 70 (5-7). Additionally, a large number of lung resections fail to meet any of the proposed criteria for lymph node examination, with up to $60 \%$ having no mediastinal lymph node evaluated (5). An article on postmortem examination of mediastinal lymph nodes reported an average of 23 lymph nodes resected, with station 7 being present $100 \%$ of the time (8). This leads us to believe that lack of mediastinal lymph nodes as part of lung resection for malignancy is not due to absence of these nodes in the patient. In this article, we review the current guidelines on intrathoracic lymph node assessment for lung cancer resections, examine current practice patterns, report survival differences with varying levels of lymph node dissection, and propose methods to improve quality of lymphadenectomy. We present the following article in accordance with the Narrative Review reporting checklist (available at https:// asj.amegroups.com/article/view/10.21037/asj-21-80/rc).

\section{Methods}

To find relevant articles for the narrative review, the
PubMed database was used to search for the following key terms and their combinations: "lymphadenectomy", "lymph node staging", "lung cancer", "NSCLC", "lung surgery", "lung resection", "lobectomy", "segmentectomy", "wedge resection", "quality", and "extent". The search was limited to English-language publications. All study design types, and time periods were included. In addition to the search, we also included articles cited by references of the initially retrieved articles. A total of 33 articles were examined, and publication years ranged from 1951 to 2021 . Two authors performed the literature review and independently found the data from the selected articles. The search strategy is summarized in Table 1.

\section{Results of the search}

\section{Current guidelines}

Intrathoracic lymph node staging includes assessment of intrapulmonary, hilar, and mediastinal lymph nodes. A guide to nomenclature was first described in 1967 by Tsuguo Naruke and has since evolved to the current map described by the International Association for the Study of Lung Cancer (IASLC) $(9,10)$. Although the need for lymph node evaluation has been well established, specific parameters as to the exact number to be resected remains debatable. Various guidelines have been proposed by the National Comprehensive Cancer Network (NCCN), American College of Surgeons Commission on Cancer (ACS CoC), the Union for International Cancer Control (UICC), American College of Surgeons Oncology Group (ACOSOG), and the IASLC among others (11-15). Recommended guidelines for intrathoracic lymph node assessment are outlined in Table 2. Moreover, inadequate lymph node assessment is now classified by the IASLC as an uncertain resection margin, $\mathrm{R} 0$ (un). 
Table 2 Societal guidelines for lymph node sampling during lung cancer resection

\begin{tabular}{|c|c|c|c|c|}
\hline Society & Year of publication & $\begin{array}{l}\text { Required number of lymph } \\
\text { node stations }\end{array}$ & Required number of nodes & Mandatory \\
\hline NCCN (12) & 2017 & 4 & - & $\mathrm{N} 1$ and at least three N2 stations \\
\hline \multirow[t]{2}{*}{ UICC (11) } & 2018 & 2 & 6 & $3 \mathrm{~N} 1$ nodes \\
\hline & & & & 3 mediastinal nodes \\
\hline \multirow{2}{*}{ IASLC (15) } & & & & $3 \mathrm{~N} 1$ nodes \\
\hline & & & & 3 mediastinal nodes \\
\hline
\end{tabular}

NCCN, National Comprehensive Cancer Network; ACS CoC, American College of Surgeons Commission on Cancer; UICC, Union for International Cancer Control; IASLC, International Association for the Study of Lung Cancer.

\section{Practice patterns}

Although it has been established that adequate lymph node assessment is an essential prognostic indicator, satisfactory evaluation is not consistent among surgeons. In a review of the Surveillance, Epidemiology, and End Results (SEER) Database, including patients from 1998 to 2002 diagnosed with non-small cell lung cancer (NSCLC), inadequate lymph node assessment was found in $62 \%$ of patients. In a European study using data from the Spanish Lung Cancer group SCAT trial, specific lymph node stations were considered. Evaluation of stations 7 and 10, with station 7 being mandatory as defined by the IASLC guidelines, were not assessed in $33.7 \%$ and $17.7 \%$ of patients, respectively (16). Additionally, $15.4 \%$ of patients with $\mathrm{N} 1$ disease did not have mediastinal lymph nodes removed, and $20.2 \%$ only had one N2 station assessed (3 being the minimum as defined by NCCN and IASLC). Consequently, 5 -year survival and lung cancer-specific survival rates were decreased in those patients without mediastinal lymph node sampling, compared to those who had mediastinal lymph node sampling ( $47 \%$ vs. $52 \%$ and $58 \%$ vs. $63 \%$ respectively, $\mathrm{P}<0.001)$. Examination of mediastinal lymph nodes resulted in a $7 \%$ decrease of all-cause mortality and $11 \%$ decrease in lung cancer specific mortality (5). A more recent study evaluated patients in the National Registry of Lung Cancer (Poland) between 2007 and 2017, and found 82.7\% to be compliant with UICC staging criteria for lymph node evaluation (17). Furthermore, adequacy of staging improved by $16 \%$ from 2008 to 2010 , suggesting greater compliance with guidelines as awareness increases. Factors reported to be associated with a decrease in adequacy of sampling included older patients (age $>64$ ), left sided tumors, sublobar resections, and stage T1 tumors (17). Survival was once again demonstrated to be significantly worse in patients with inadequate lymph node assessment (17). Similarly, David et al. studied the California Cancer Registry from 2004 to 2011, assessing lymph node patterns and effects on survival (18). This data corroborated the negative effect of inadequate lymph node assessment, reporting 5-year overall survival of $42.6 \%$ for zero resected nodes vs. $54.6 \%$ for more than 10 resected nodes. Once again, patients with sublobar resections were less likely to undergo adequate lymph node examination (18).

With more pervasive use of low dose computed tomography (CT) for lung cancer screening, there has an increase in detection of early-stage tumors smaller than 1-2 cm and correspondingly an increase in sublobar resections, namely anatomical segmentectomies (19). Several studies using national databases have shown sublobar resections to be associated with lesser lymph nodes resected with $40-70 \%$ of patient with no lymph node sampling $(20,21)$. Although many may argue of the value of lymphadenectomy with early-stage lung cancer, nodal upstaging may be seen in $15-20 \%$ of patients with stage I NSCLC. Moreover, those patients who undergo segmentectomy with mediastinal lymphadenectomy show increased survival compared to those patients with only hilar lymph node sampling (22). Given this data, several authors have sought to investigate whether segmentectomy allows for adequate staging. Mattioli and colleagues performed a single institution study comparing patients undergoing anatomical segmentectomy with lobectomies and found similar number of median lymph nodes dissected in both N1 and N2 stations in the two groups (19). This leads us to believe that adequate 

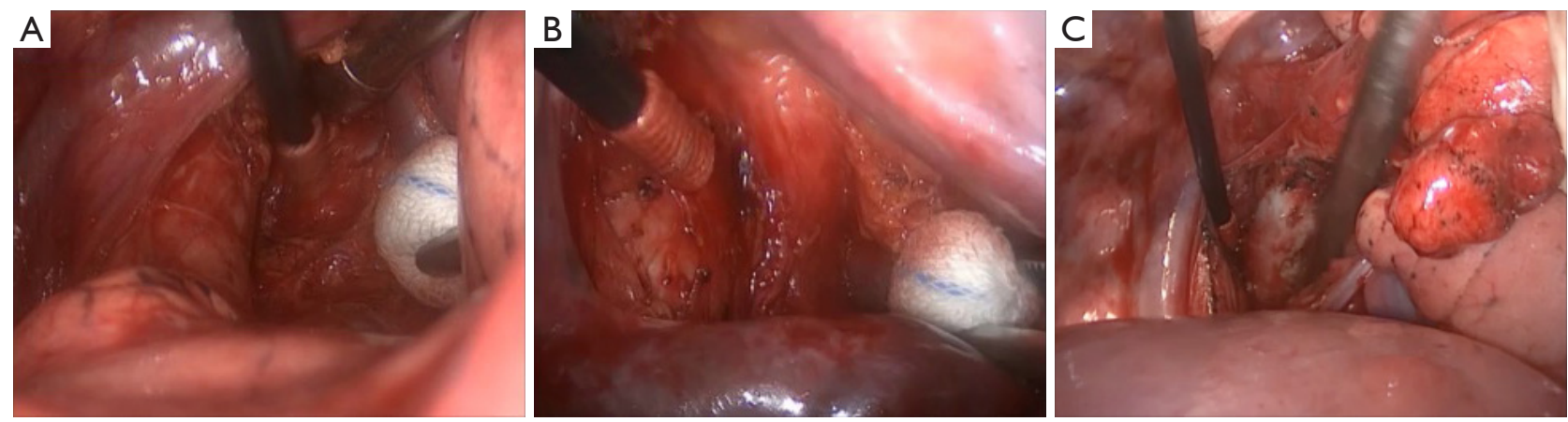

Figure 1 Mediastinal lymph node dissection of stations 4R (A), 2R (B), and 7 (C) by right video-assisted thoracoscopic surgery.

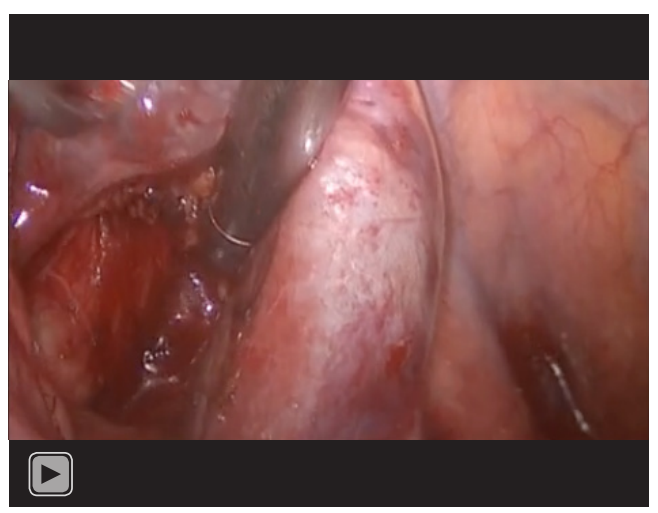

Video 1 Dissection of the station $4 \mathrm{R}$ and $2 \mathrm{R}$ lymph node packet by right video-assisted thoracoscopic surgery, starting below the azygous vein, and moving proximally.

lymphadenectomy is feasible during sublobar resections and should be performed whenever possible.

In an effort assess gaps in quality of lymph node evaluation, Osarogiagbon et al. compared surgeons' reported lymph node examination with samples received by the pathologist (23). The concordance rate between the operating surgeons and pathologist was only $39 \%$, suggesting what is perceived as adequate lymph node evaluation, is many times suboptimal. Over $40 \%$ of patients in this study had no mediastinal lymph node sampled (23). The authors concluded that the quality gap was likely due to poor surgical collection, issues with specimen transfer, and poor pathological examination.

\section{Discussion}

\section{Extent of lymph node dissection}

The term optimum extent or sufficient lymph node dissection is controversial. There is no clear data to demonstrate a significant survival benefit of complete removal of the lymph nodes $v s$. sampling (24). Approaches to right and left paratracheal compartments differs for tumors of the right and left lung. For a right-sided NSCLC, paratracheal lymph nodes can be removed completely (Figure 1, Video 1). For left sided tumors, complete resection of paratracheal nodes may pose to be more challenging, but has been performed by several authors, including one of the authors of this manuscript (Figure 2, Video 2) (25). Bilateral paratracheal lymph node dissection has also been performed and presented for right and left sided tumors. Postoperative outcomes were demonstrated to be similar, apart from transient left recurrent nerve palsy which was seen in patients with left sided bilateral paratracheal dissection which includes stations 2L, 2R, 4L, and 4R (Figure 3). Before this technique was developed, several authors recommended and performed median sternotomy for removal of bilateral paratracheal lymph nodes (26). Methods of bilateral lymph node dissection include left thoracotomy with aortic arch mobilization, video assisted lymphadenectomy with mediastinoscopy, and transcervical extended lymphadenectomy (27-29). Our standard lymph node dissection in open thoracotomy includes removal of all ipsilateral mediastinal lymph nodes (Video 2, Figure 3). Whether an open, video-assisted thoracoscopic surgery (VATS) or robotic case, the extent of lymph node dissection must be complete and the same. In a study comparing open $v s$. VATS $v s$. robotic approaches for lymph node dissection in lung cancer, the authors founds that all three methods can provide a similar number of hilar and mediastinal lymph node stations, although the number of hilar and interlobar nodes may be more with the robotic approach (30). 


\section{Future direction}

In order to increase prevalence and quality of lymph node assessment in lung cancer resection, Osarogiagbon and colleagues proposed use of a lymph node collection kit intraoperatively (31). This kit consisted of pre-labelled cups

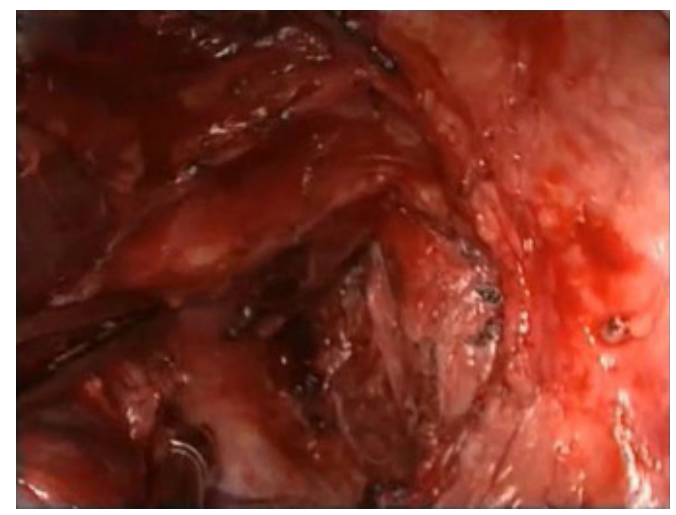

Figure 2 Dissection of station 7 lymph nodes via left video-assisted thoracoscopic surgery.
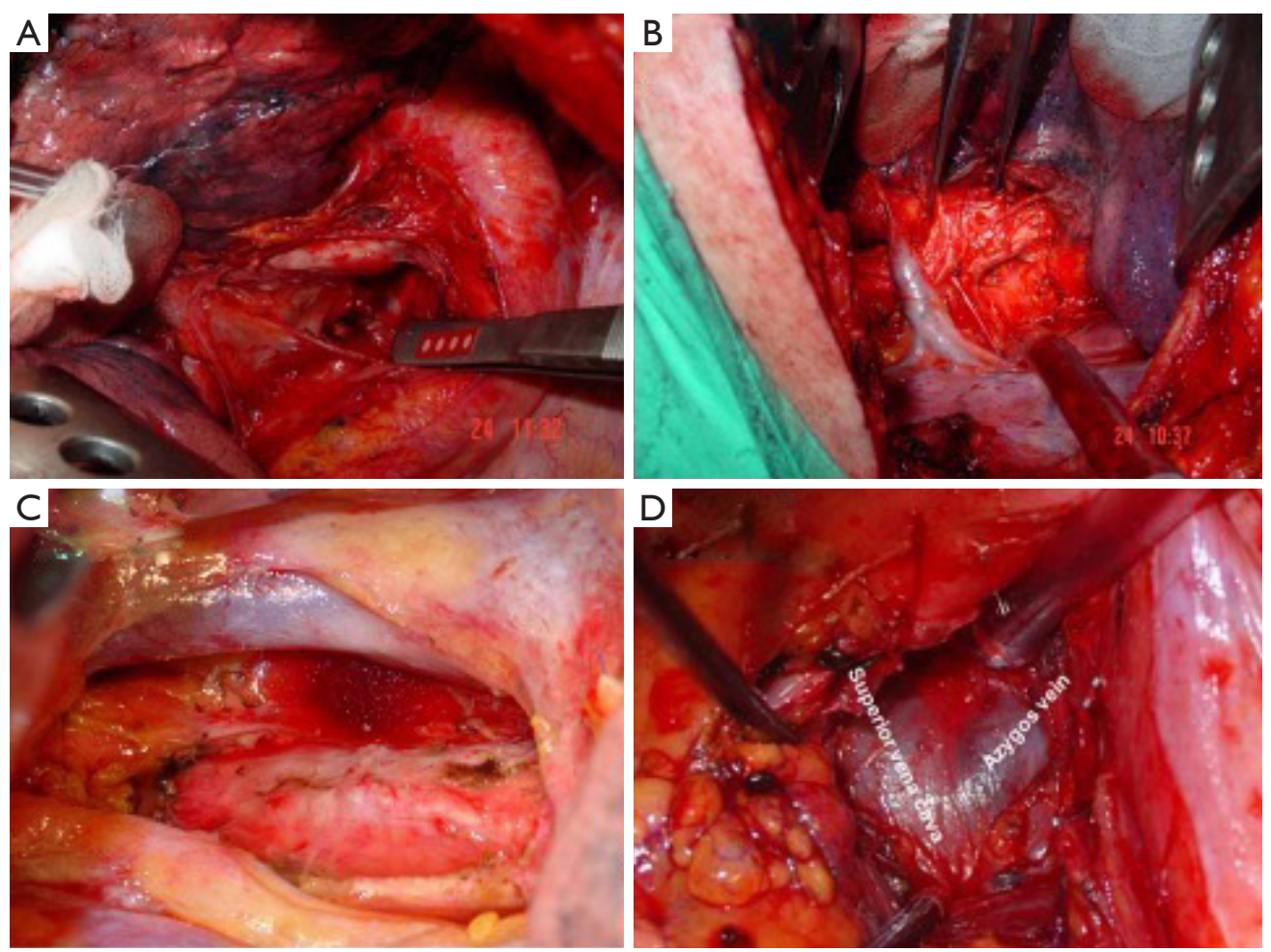

Figure 3 Complete lymph node dissection during open surgery, generally reserved for clinical T3-4 and N1-0 tumors. (A,B) Dissection of the subcarinal station from the left side and right side respectively. (C) En-bloc resection of $2 \mathrm{R}$ and $4 \mathrm{R}$ lymph nodes. (D) Extensive dissection of bilateral paratracheal lymph nodes from the left aorto-pulmonary window. node map using the IASLC nomenclature (32). In addition, separate kits were available for right and left sided resections, indicating which lymph node stations were mandatory. Use of the collection kit resulted in $73 \%$ of the study population

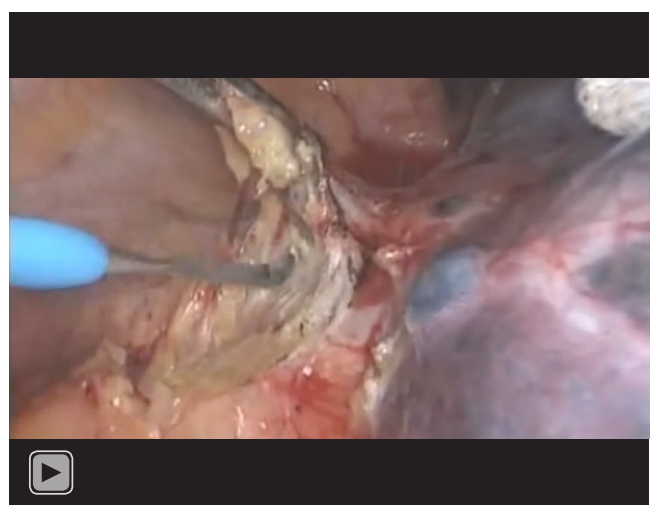

Video 2 Dissection of station 5 and station 7 lymph nodes via left video-assisted thoracoscopic surgery. 
having adequate lymph node assessment. Moreover, the concordance rate between surgeon and pathologist regarding lymph node evaluation increased from $39 \%$ to $80 \%$ (31). In a follow up study, heightened awareness was added as a measure to improve suboptimal lymph node evaluation, and although it did result in increased quality of surgical resection and pathological assessment, use of a specimen collection kit was the most effective tool (33).

\section{Limitations}

The main limitation of this narrative review is the heterogeneity of studies included, with many being retrospective in nature. There also may be an element of selection bias inherent to narrative reviews. Despite these limitations, we believe the information presented provides a good overview of the current status of lymphadenectomy performed during lung resections. Given the varying guidelines and lack of randomized control studies in this area, further research is necessary to decide the optimal extent of lymphadenectomy in lung cancer surgery.

\section{Final words}

The extent and quality of lymph node dissection is based on several parameters. Although several definitions have been presented, we believe, the extent and aggressiveness of lymph node dissection should be related to the following factors:

(I) The clinical stage of disease, given that micrometastatic lymph node involvement increases with T stage;

(II) PET CT findings showing hypermetabolic mediastinal lymph node activity;

(III) Surgery after a neoadjuvant treatment due to previous N2 positivity;

(IV) Presence of bilateral NSCLC (2 primary lung tumors), and

(V) The fragility of the patient.

The quality of lymph node dissection depends on the following other factors:

(I) Optimum approach with VATS or Robotic surgery ensuring proper port placement;

(II) Appropriately positioned thoracotomy (too low of an interspace may limit the quality of lymph node dissection);

(III) Instrumentation used for dissection of lymph nodes (robotic instruments may be superior according to some authors);

(IV) Complete removal of the nodes rather than piecemeal;

(V) And above all, the quality of LN dissection depends on the surgeon's enthusiasm and wish to perform a complete resection.

Systematic mediastinal lymph node dissection is recommended in all type of lung cancer surgeries whether it is robotic surgery, VATS, or an open thoracotomy. There should be no difference in each technique as to the number of stations and quantity of lymph nodes examined, in order for lung cancer resection to be considered complete. In patients with $\mathrm{T} 1$ tumors, hilar and interlobar nodes need to be evaluated with frozen section studies, this may help decide whether to perform just a sampling from mediastinum in elderly and fragile patients $v s$. a complete dissection. If this is not possible, and in all patients, we recommend performing systematic mediastinal assessment. The pathologist needs to report and describe the number of lymph nodes removed and analyzed. The number of metastatic lymph nodes in each station, and the integrity of the lymph node capsule should be reported. The quality of lymph node dissection can then be understood from the final pathology report.

\section{Summary}

Systematic mediastinal lymph node dissection is recommended in all type of surgeries for lung cancer, whether robotic surgery, VATS, or an open thoracotomy. Differences in guidelines may be a source of confusion as to the ideal number of lymph nodes and stations to be resected. Heightened awareness and use of specimen collection kits may increase the quality of lymph node resection. Given the varying recommendations for intrathoracic lymph node assessment, further research is necessary to decide the optimal extent of lymphadenectomy in lung cancer surgery.

\section{Acknowledgments}

Funding: None.

\section{Footnote}

Provenance and Peer Review: This article was commissioned by the Guest Editor (Hitoshi Igai) for the series "Lymphadenectomy in Thoracoscopic Surgery" published in AME Surgical fournal. The article has undergone external 
peer review.

Reporting Checklist: The authors have completed the Narrative Review reporting checklist. Available at https:// asj.amegroups.com/article/view/10.21037/asj-21-80/rc

Peer Review File: Available at https://asj.amegroups.com/ article/view/10.21037/asj-21-80/prf

Conflicts of Interest: All authors have completed the ICMJE uniform disclosure form (available at https://asj.amegroups. com/article/view/10.21037/asj-21-80/coif). The series "Lymphadenectomy in Thoracoscopic Surgery" was commissioned by the editorial office without any funding or sponsorship. AT serves as an unpaid editorial board member of AME Surgical Fournal from December 2020 to November 2022. The authors have no other conflicts of interest to declare.

Ethical Statement: The authors are accountable for all aspects of the work in ensuring that questions related to the accuracy or integrity of any part of the work are appropriately investigated and resolved. All procedures performed in this study were in accordance with the Helsinki Declaration (as revised in 2013). The publication of this manuscript is waived from patient informed consent according to the ethics committee or institutional review board.

Open Access Statement: This is an Open Access article distributed in accordance with the Creative Commons Attribution-NonCommercial-NoDerivs 4.0 International License (CC BY-NC-ND 4.0), which permits the noncommercial replication and distribution of the article with the strict proviso that no changes or edits are made and the original work is properly cited (including links to both the formal publication through the relevant DOI and the license). See: https://creativecommons.org/ licenses/by-nc-nd/4.0/.

\section{References}

1. Sung H, Ferlay J, Siegel RL, et al. Global Cancer Statistics 2020: GLOBOCAN Estimates of Incidence and Mortality Worldwide for 36 Cancers in 185 Countries. CA Cancer J Clin 2021;71:209-49.

2. CAHAN WG, WATSON WL, POOL JL. Radical pneumonectomy. J Thorac Surg 1951;22:449-73.
3. Asamura H, Chansky K, Crowley J, et al. The International Association for the Study of Lung Cancer Lung Cancer Staging Project: Proposals for the Revision of the N Descriptors in the Forthcoming 8th Edition of the TNM Classification for Lung Cancer. J Thorac Oncol 2015;10:1675-84.

4. D'Cunha J, Herndon JE 2nd, Herzan DL, et al. Poor correspondence between clinical and pathologic staging in stage 1 non-small cell lung cancer: results from CALGB 9761, a prospective trial. Lung Cancer 2005;48:241-6.

5. Osarogiagbon RU, Yu X. Mediastinal lymph node examination and survival in resected early-stage non-smallcell lung cancer in the surveillance, epidemiology, and end results database. J Thorac Oncol 2012;7:1798-806.

6. Darling GE, Allen MS, Decker PA, et al. Number of lymph nodes harvested from a mediastinal lymphadenectomy: results of the randomized, prospective American College of Surgeons Oncology Group Z0030 trial. Chest 2011;139:1124-9.

7. Osarogiagbon RU, Ogbata O, Yu X. Number of lymph nodes associated with maximal reduction of long-term mortality risk in pathologic node-negative non-small cell lung cancer. Ann Thorac Surg 2014;97:385-93.

8. Ziyade S, Pinarbasili NB, Ziyade N, et al. Determination of standard number, size and weight of mediastinal lymph nodes in postmortem examinations: reflection on lung cancer surgery. J Cardiothorac Surg 2013;8:94.

9. Naruke T, Suemasu K, Ishikawa S. Lymph node mapping and curability at various levels of metastasis in resected lung cancer. J Thorac Cardiovasc Surg 1978;76:832-9.

10. Rusch VW, Asamura H, Watanabe $\mathrm{H}$, et al. The IASLC lung cancer staging project: a proposal for a new international lymph node map in the forthcoming seventh edition of the TNM classification for lung cancer. J Thorac Oncol 2009;4:568-77.

11. Smeltzer MP, Faris NR, Ray MA, et al. Association of Pathologic Nodal Staging Quality With Survival Among Patients With Non-Small Cell Lung Cancer After Resection With Curative Intent. JAMA Oncol 2018;4:80-7.

12. Ettinger DS, Wood DE, Aisner DL, et al. Non-Small Cell Lung Cancer, Version 5.2017, NCCN Clinical Practice Guidelines in Oncology. J Natl Compr Canc Netw 2017;15:504-35.

13. Surgeons. ACo, Measures. CQoC. CoC Measures for Quality of Cancer Care 2014. Available online: http://www. facs.org/quality-programs/cancer/ncdb/qualitymeasures

14. Allen MS, Darling GE, Pechet TT, et al. Morbidity and 
mortality of major pulmonary resections in patients with early-stage lung cancer: initial results of the randomized, prospective ACOSOG Z0030 trial. Ann Thorac Surg 2006;81:1013-9; discussion 1019-20.

15. Rami-Porta R. The Evolving Concept of Complete Resection in Lung Cancer Surgery. Cancers (Basel) 2021;13:2583.

16. Jarabo Sarceda JR, Bolufer Nadal S, Mongil Poce R, et al. Spanish Lung Cancer Group SCAT trial: surgical audit to lymph node assessment based on IASLC recommendations. Transl Lung Cancer Res 2021;10:1761-72.

17. Pawelczyk K, Blasiak P, Szromek M, et al. Assessment of adequacy of intraoperative nodal staging and factors influencing the lack of its compliance with recommendations in the surgical treatment of non-small cell lung cancer (NSCLC). J Thorac Dis 2018;10:4902-11.

18. David EA, Cooke DT, Chen Y, et al. Does Lymph Node Count Influence Survival in Surgically Resected Non-Small Cell Lung Cancer? Ann Thorac Surg 2017;103:226-35.

19. Mattioli S, Ruffato A, Puma F, et al. Does anatomical segmentectomy allow an adequate lymph node staging for cT1a non-small cell lung cancer? J Thorac Oncol 2011;6:1537-41.

20. Razi SS, John MM, Sainathan S, et al. Sublobar resection is equivalent to lobectomy for T1a non-small cell lung cancer in the elderly: a Surveillance, Epidemiology, and End Results database analysis. J Surg Res 2016;200:683-9.

21. Thomas PA. Lymph node dissection during sublobar resection: why, when and how? J Thorac Dis 2018;10:S1145-50.

22. Handa Y, Tsutani Y, Mimae T, et al. Appropriate Extent of Lymphadenectomy in Segmentectomy: A Multicenter Study. Jpn J Clin Oncol 2021;51:451-8.

23. Osarogiagbon RU, Allen JW, Farooq A, et al. Objective review of mediastinal lymph node examination in a lung cancer resection cohort. J Thorac Oncol 2012;7:390-6.

24. Wright G, Manser RL, Byrnes G, et al. Surgery for nonsmall cell lung cancer: systematic review and meta-analysis

doi: $10.21037 /$ asj-21-80

Cite this article as: Kakuturu J, Abbas G, Toker A. Evaluating the quality of lymphadenectomy in lung cancer resections: a narrative review. AME Surg J 2022;2:8. of randomised controlled trials. Thorax 2006;61:597-603.

25. Toker A, Tanju S, Ziyade S, et al. Alternative paratracheal lymph node dissection in left-sided hilar lung cancer patients: comparing the number of lymph nodes dissected to the number of lymph nodes dissected in rightsided mediastinal dissections. Eur J Cardiothorac Surg 2011;39:974-80.

26. Hata E, Miyamoto H, Tanaka M, et al. The necessity of extended systemic dissection of the regional lymph node in radical operation for lung cancer. Kyobu Geka 1994;47:40-4.

27. Zieliński M. Transcervical extended mediastinal lymphadenectomy: results of staging in two hundred fiftysix patients with non-small cell lung cancer. J Thorac Oncol 2007;2:370-2.

28. Watanabe Y, Shimizu J, Oda M, et al. Improved survival in left non-small-cell N2 lung cancer after more extensive operative procedure. Thorac Cardiovasc Surg 1991;39:89-94.

29. Leschber G, Holinka G, Linder A. Video-assisted mediastinoscopic lymphadenectomy (VAMLA)--a method for systematic mediastinal lymphnode dissection. Eur J Cardiothorac Surg 2003;24:192-5.

30. Toker A, Özyurtkan MO, Demirhan Ö, et al. Lymph Node Dissection in Surgery for Lung Cancer: Comparison of Open vs. Video-Assisted vs. Robotic-Assisted Approaches. Ann Thorac Cardiovasc Surg 2016;22:284-90.

31. Osarogiagbon RU, Sareen S, Eke R, et al. Audit of lymphadenectomy in lung cancer resections using a specimen collection kit and checklist. Ann Thorac Surg 2015;99:421-7.

32. Osarogiagbon RU, Miller LE, Ramirez RA, et al. Use of a surgical specimen-collection kit to improve mediastinal lymph-node examination of resectable lung cancer. J Thorac Oncol 2012;7:1276-82.

33. Ray MA, Fehnel C, Akinbobola O, et al. Comparative Effectiveness of a Lymph Node Collection Kit Versus Heightened Awareness on Lung Cancer Surgery Quality and Outcomes. J Thorac Oncol 2021;16:774-83. 